\title{
Meaning of Life Orientations of TB-Infected Male Convicts: Analysis of the Pilot Research
}

\author{
Irina Ganishina \\ Academyof Law and Management of the Federal Penal \\ Service of Russia \\ Ryazan, Russian Federation \\ irinaganishina@yandex.ru \\ Natalia Ilyinykh \\ Academyof Law and Management of the Federal Penal \\ Service of Russia \\ Ryazan, Russian Federation \\ ilinykh1983@mail.ru \\ Ekaterina Kholopova \\ Academyof Law and Management of the Federal Penal \\ Service of Russia \\ Ryazan, Russian Federation \\ ek.holopova@yandex.ru
}

\author{
Emilia Komarova \\ Voronezh State Technical University \\ Voronezh, Russian Federation \\ vivtkmk@mail.ru
}

\author{
Alexander Fetisov \\ Central Branch of the Russia State University of Justice \\ Voronezh, Russian Federation \\ asfet-2011@mail.ru
}

\begin{abstract}
Today in Russia proportion of TB-infected male convicts serving sentences in prisons has significantly increased. According to the data of domestic and foreign scientists (R. May, V. Frankl, A. Adler, D.A. Leontiev, A.I. Ushatikov, V.G. Deev, D.V. Sochivko, etc.), the formation of meaning of life orientations has a positive impact on the psychological state of an individual and positively correlates with the effectiveness of the treatment. In 2018, in order to study the personal characteristics of TBinfected male convicts and to determine the level of formation of their meaning of life orientations, the pilot study in the medical and correctional institution of the Russian Federation was conducted. Special attention was paid to identifying the personal (criminal, socio-demographic, medical, individual psychological) characteristics of TB-infected male convicts. The research was carried out with the help of a set of psychodiagnostic methods and techniques: observation, conversation, praximetric method (analysis of personal files and medical records), testing, the test "Methods of studying character accentuations" (H. Smishek, K. Leongard), the test "Meaning of life orientations". (D.A. Leontiem), Lusher's test, methods of mathematical statistics (correlation analysis). It was found that TB-infected male convicts are characterized by negative mental states, character accentuation, low level of formation of meaning of life orientations.
\end{abstract}

Keywords: penal system, medical and correctional institution, TB-infected male convicts, male inmates, meaning of life orientations, personal features of TB-infected male convicts

\section{INTRODUCTION}

Tuberculosis belongs to the group of socially significant incurable diseases. According to the data of the International Classification of Diseases (ICD) of the 10th revision of ICD10 , tuberculosis is considered as infectious diseases (index A15-19), which include tuberculosis of the respiratory system, nervous system, bones and joints, genitourinary organs, etc. [1].

For the past five years in Russia, active forms of tuberculosis were first detected in 356,526 people, which includes 49 cases per 100,000 people [2]. The urgency of combating this bacteriological disease for a long time occupies the first place in the epidemiological policy of the country. The criminal Executive system of the Russian Federation was no exception according to statistics, more than 40,000 TBinfected male convicts are serving their sentences in prison in the penitentiary system [3]

\section{METHODS}

Theoretical and methodological analysis of domestic and foreign literature has shown that isolation from society as a socially significant change in a person's life significantly affects his meaning of life orientations. The research of meaning of life orientations of TB-infected male convicts was developed by R. May [4], who believed that diseases occur due to the inability of a man to see his own meaning of life 
orientation. According to A. Adler [5] the understanding the purpose of life makes it possible to realize the hidden meaning that lies on the basis of all human actions. D. A. Leontiev [6] linked with the loss of health with the loss of the meaning of life orientations of human existence [7, 8]. V. Frankl [9] wrote that the stronger the orientation of a person on the meaning of life, the more significantly his health is strengthened and the life is prolonged.

Penitentiary psychologists (A.I. Ushatikov [10], I. S. Ganishina [10], V. G. Deev [11], D. V. Sochivko [12], A.V. Napris [13], N. A. Polyanin [14], etc.) argue that the health of the convicted person is a unity of physical, social and psychological components. Consequently, the increase of one component leads to an increase of the other, which generally contributes to the improvement of the convict's health. Meaning of life orientations to the mind of prison psychologists, are dual and contradictory $[15,16]$. The meaning sphere of the convicted person while serving a punishment varies with changing conditions, experience, orientation of the personality, personal features, landmarks, social environment, therefore, the research meaning of life orientations of TB-infected male convicts prisoners is urgent to science $[17,18]$.

V.G. Deev [11], A.I. Ushatikov [10] considered the personality of the convict as asubject of penitentiary psychology. To the mind of D.V. Sochivko [12] the personality of the convict is consideredas a special structure taking into account temporary formations, criminal contamination, health or illness. According to A.V. Napris [13] the psychological characteristics of the life plans of convicts, focusing on their meaning of life orientations. According to N.A. Polyanin [14] the personality of the convict takes into account socio-economic, moral, social and psychological aspects. A.I. Ushatikov, I. S. Ganishina, G.I. Aksenova, P.Y. Aksenova [10, 19] recommend to consider psychological features of the TB-infected male convicts taking into account socially-demographic, criminal-legal, medical features.

The goal of the researchis to study the meaningof life orientations of TB-infected male convicts.

Methods and techniques: observation, conversation, praximetric method (analysis of personal files and medical records), testing, test "Methods of research of character accentuations" (H. Smishek, K. Leonhard), test "Meaning of life orientations" (D. A. Leontiev), Lusher test, methods of mathematical statistics (correlation analysis).

Scientific novelty of research consists of definition of meaning of life orientations of TB-infected male convicts.

\section{RESULTS}

In 2018, the pilot research has been conducted in the medical and correctional institution of the Russian Federation for the maintenance of TB-infected male convicts in order to identify their meaning of life orientations [20]. The research involved 45 TB-infected male convicts. Taking into account the unity of the physical, social and psychological components of the personal health [21] of convicted persons, their criminal, socio-demographic [22], medical [23] and individual psychological characteristics have been studied.

Investigating criminal-legal peculiarities, the articles of conviction, average term of imprisonment, regime of serving the sentence, presence/absence of recidivism, number of criminal convictions have been established using the praximetric method.

After analyzing the articles on which TB-infected male convicts were convicted, the articles of the Criminal Code of the Russian Federation on which they serve their sentences have been established: Article 158 of the Criminal Code (theft) - 36 per cent; article 105 of the Criminal Code (killing) - 22 per cent; and article 228 of the Criminal Code (illegal acquisition, storage, transportation, manufacture, processing of narcotic drugs, psychotropic substances or their analogues) 16 per cent; Article 111 of the Criminal Code (intentional infliction of serious harm to health) - 9 per cent; article 161 of the Criminal Code (pillage) - 4 per cent; article 162 of the Criminal Code (robbery) - 4 per cent; article 115 of the Criminal Code (intentional infliction of minor harm to health) - 4 per cent; article 119 of the Criminal Code (threat of murder or serious harm to health) - 4 per cent. Consequently, the majority of convicted persons with TB-infected are serving criminal sentences under mercilessly violent articles.

The duration of the sentence for TB-infected male convicts varies from one to 25 years: Up to 2 years' deprivation of liberty - 29 per cent; up to 3 years' deprivation of liberty - 20 per cent; from 10 to 15 years' deprivation of liberty - 13 per cent; up to 8 years' deprivation of liberty - 11 per cent; from 15 to 20 years' deprivation of liberty - 7 per cent; up to 4 years' deprivation of liberty - 4 per cent; up to 6 years' deprivation of liberty - 4 per cent; up to 9 years' deprivation of liberty - 4 per cent; up to 1 year' deprivation of liberty - 2 per cent; up to 5 years' deprivation of liberty - 2 per cent; up to 7 years' deprivation of liberty - 2 per cent; and from 20 to 25 years' deprivation of liberty - 2 per cent. Consequently, the majority of male convicts who are TB-infected tend to commit crimes of medium gravity, for which a term of deprivation of liberty of two to three years is set.

Higly TB-infected male convicts serve their sentences in maximum security penal colonies (74 per cent). Thirteen per cent TB-infected male convicts were sentenced to serve their sentences in a general-regime prison and 13 per cent in a special-regime prison.

The majority of male prisoners with TB-infected male convicts (84 per cent) have been convicted on several occasions: 2 (29 per cent), 3 (20 per cent), 4 (16 per cent), 5 (4 per cent), 6 (4 per cent), 7 (4 per cent), 8 (4 per cent) and 10 (2 per cent).

After analyzing the criminal experience of TB-infected male convicts, it can be concluded that the majority of them (62\%) are recidivists, with $40 \%$ recognized as recidivists, 11 $\%$ - dangerous recidivists, $11 \%$ have a particularly dangerous recidivism. Consequently, the majority of male prisoners who are TB-infected are repeated offenders and have repeatedly committed criminal offences. 
Analysis of socio-demographic peculiarities of TBinfectedmale convicts using the praximetric method shows us that the age of convicts under 40 years old is $22 \%$; under 45 years old $-22 \%$; under 35 years old $-16 \%$; under 50 years old $-22 \%$; under 30 years old $-11 \%$; under 55 years old -7 $\%$; under 25 years old $-2 \%$; under 60 years old $-2 \%$; over $60 \%-2 \%$. It has been established that the majority of male prisoners who have been TB-infected (76 per cent) are between the ages of 35 and 50 .

After analyzed the level of education of TB-infected convicts, it has been established that 29 per cent of the convicts had secondary education, 33 per cent had primary vocational education and 38 per cent had incomplete secondary education. It has been established that all TBinfected convicts do not have higher education.

The majority of TB-infected convicts are unmarried or divorced (82 per cent). This indicates that they are single, unable to establish social contact with women of the opposite sex, or have lost social ties while serving their sentence.

Prior to conviction, the majority of TB-infected male convicts (78 per cent) had no profession, did not work anywhere, and were engaged in tunneling [24].

The analysis of the medical records of TB-infected male convicts showed that they were diagnosed with various forms of tuberculosis: 58 per cent infiltration, 22 per cent disseminated tuberculosis, 16 per cent fibrous cavernous tuberculosis and 4 per cent focal tuberculosis [25]. The majority of tuberculosis patients are burdened with HIVrelated $(26 \%)[26,27]$ or psychosomatic disease (diabetes, neurosis, hypertension, heart disease) - $52 \%$ [23].

To diagnose individual psychological peculiarities of TBinfected male convicts, a set of psychodiagnostic methods and techniques such as: observation, conversation, testing, the "Methods of character accentuation research" test $(\mathrm{H}$. Smishek, K. Leongard) [28, 29], the "Meaningless of life orientations" test (D.A. Leontiev) [30], Lusher's test [31], methods of mathematical statistics (correlation analysis) have been used.

In order to exclude psychopathological disorders in TBinfected male convicts, the "Method of character accentuation research" (H. Smyshek, K. Leongard) has been used. It was aimed at studying the level and type of personality accentuation. It was found that TB-infected male convicts showed high levels of emotion and exaltedness (Figure 1), which characterized them as people with high sensitivity and deep reactions in the field of fine emotions. They are characterized by violent reactions: they are easily delighted with joyful events and desperate for sadness, they are characterized by extreme sensitivity about sad events and facts of their own lives. They have somewhat increased scales of hyperactivity, stuckness, pedantry, cyclotism, therefore, they are characterized by sociability, increased wordishness, external accuracy, craving for order, indecisiveness, caution, slowness of reactions and thinking, reduction of emotional response, etc. Low rates of anxiety scale indicate, on the one hand, that TB-infected male convicts are adapted to tubinfection and, on the other hand, to places of detention. The results of research using the "Method for the study of character accentuations" (H. Smishek, K. Leongard) indicate the presence of character accentuations in TB-infected male convicts, which affect their meaning of life orientation.

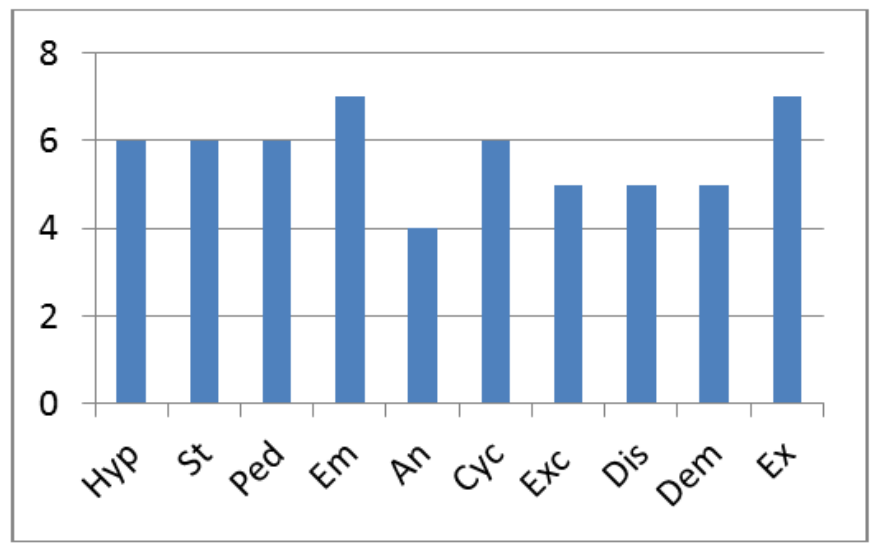

Fig. 1. Average values in the group of male prisoners who are TB-infected Method for the study of character accentuations (H. Smyshek, K. Leongard) (Hyp (Hyperactivity), St (Stuck), Ped (Pedantry), Em (Emotivism), An (Anxiety), Cyc (Cyclotimia), Exc (Excitability), Dis (Distigmatism), Dem (Demonstrativeness), Ex (Exaltation))

The findings of the "Meaning of life orientation" (D.A. Leontiev) (Figure 2) show that the TB-infected male convicts have slightly higher than the average level of Locus control I'm (I am the master of life), which indicates the existence of goals in their lives which they see in the future, which gives meaning of life orientationand a temporary perspective to their lives. The average level on the "Goals in life" scale indicates a reduced level of life efficiency and dissatisfaction with selfactualization. They have slightly lower scores on the scales of "Process of life, interest and emotional saturation", which indicates a lack of satisfaction with the lived part of life. On the scale of "Locus of control - life, or controllability of life", subjects are characterized by the belief that their lives are not subject to enough conscious control and it is meaningless to make plans for the future. Therefore, TB-infected male convicts have an insufficient (below average) level of formation of meaningful orientations, which indicates the need for their further formation.

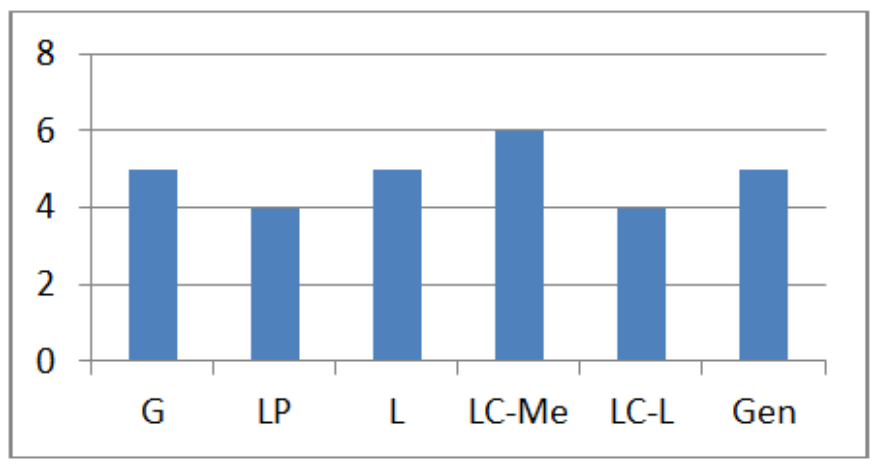

Fig. 2. Average values in the group of TB-infected male prisoners who are TB-infected male convicts on the "Meaning life of Orientations" method (D.A. Leontiev) (G (Gosls in life), LP (Lifestyle process, interest and emotional saturation), L (Life-efficiency, satisfaction with self-realization), 
LC-Me (Locus of Control (I'm a master of Life)), LC-L (Loke of Control of Life), Gen (General indicator of meaning of life orientations))

According to the results of psychodiagnostic examination by Lusher's test method (Figure 3), TB-infected male convicts male prisoners have a low level on the scales of "Constructive Behaviour", "Selectivity", "Resistance", "Dreaminess", "Sensual-aesthetic pleasure", which indicates a propensity to disease (TB-infected), low resistance of the body. They are characterized by low level of controllability, predominance of emotional component over rational one when reacting to life situations, straightforwardness, weak level of organism's ability to defend itself from negative influence from outside, tendency to inaction. The results of the method indicate the prevalence of negative mental states which do not contribute to the cure from TB-infected.

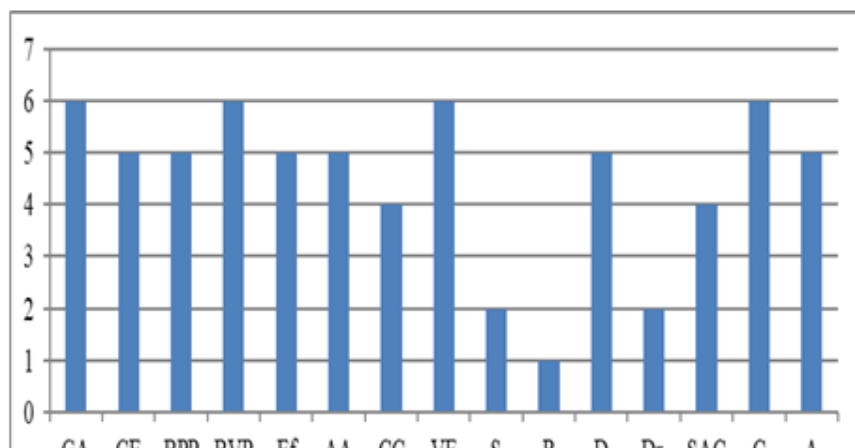

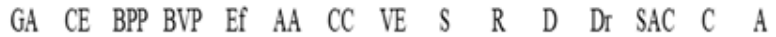

Fig. 3. Average values in the group of TB-infected male inmates using the Lusher test method (GA (Heteronomics-autonomous), CE (ConcentricityEccentricity), BPP (Personal Properties), BVP (Vegetative Properties), Ef (Operational Excellence), AA (Disadaptability), CC (Constructive Behavior), VE (Volatile tension), S (Selectivity), R (Resistibility), D (Distance), Dr (Dreaminess), SAC (Sensual Aesthetic pleasure), C (Conflict), A (Activity))

\section{DISCUSSION}

Psychometric Expert computer program (version 9.0.7) is used to process the data. Using the method of mathematical statistics (correlation analysis) it was stated the dissymmetry index according to the "Method of character accentuation research" (H. Smishek, K. Leongard) is in the reverse correlation with the locus control $-\mathrm{I}$ am $(-0,289 *)$ in the test "Meaning of Life orientation" (D.A. Leontiev), i.e. the lower the distimatism, the higher the locus of control - I am. The correlation analysis between the "Method of character accentuation research" (H. Smishek, K. Leongard) and Lusher's test showed that cyclotimia is inversely correlated with activity $\left(-0,326^{*}\right)$, and pedantry - in direct correlation with vegetative properties of personality $\left.(0,31)^{*}\right)$. The analysis of the obtained data indicates that the average level of distigmatism is the result of the increased Locus of Control - I am, and the increased level of cyclotimia is the result of reduced activity; the increased pedantry leads to increasing in vegetative manifestations of the disease in TB-infected male convicts.

Thus, the theoretical and empirical analysis of the problem of studying the meaning of life orientation of TB-infected male convicts allowed us to identify their criminal, socio- demographic, medical, individual psychological features in the medical and psychological care of the Russian Federation.

\section{CONCLUSION}

The conducted pilotresearch of the meaning of life orientations of TB-infected male convicts allowed us to draw the following conclusions:

1. Analysis of criminal-legal features showed that the majority of TB-infected mail convicts (36\%) convicted of theft for 2-3 years (49\%) served his sentence in a maximum security prison, repeatedly tried $(84 \%)$ and recognized as repeated offenders $(62 \%)$.

2. The research of the socio-demographic characteristics of highly infected male convicts led us to conclude that the majority of convicts is between the ages of 35 and 50 (76\%), have a full secondary education (38\%), are unmarried (82\%), have no profession, have not worked anywhere before conviction $(78 \%)$.

3. The research of the medical characteristicsof TBinfected male convicts allowed them todiagnose various forms of tuberculosis: infiltration tuberculosis - $58 \%$, dissected tuberculosis - $22 \%$, fibrous-cavernous tuberculosis - $16 \%$, focal tuberculosis $-4 \%$. Most of the convicts have an TBinfection $(26 \%)$ and HIV-related $(26 \%)$ or psychosomatic disease $(52 \%)$.

4. Using of psycho-diagnostic methods allowed us to identify the individual-psychological features of TB-infected convicts. Convicts have high rates of emotiveness and exaltation, hypersensitivity, and manifestations on the scale of anxiety. In TB-infected male convicts, the propensity for the disease, low resistance of the body tubinfection have been detected. Those TB-infected male convicts have insufficient levels offormbased on meaning oflife orientations.

5. It is necessary to form meaning of life orientation of TB-infected male convicts with the help of psychological and educational programs.

\section{REFERENCES}

[1] "On improving TB control in the Russian Federation", Order of the Ministry of Health of the Russian Federation dated March 21, 2003, no. 109 (as amended on October 29, 2009).

[2] Electronic resource. Available at: https://www.rospotrebnadzor.ru/activities/statistical-materials/ (Accessed: 06 October 2019).

[3] Electronic resource. Available at: https://pda.fsin.su/statistics/ (Accessed: 16 November 2019).

[4] R. May, "The Meaning of Anxiety", N.Y.: "Pocket Books", 1977.

[5] A. Adler, "Praxis und Theories der Individual psychologie", 4 Aufl, Munch, 1920, 22 p.

[6] D. A. Leontiev, "Psychology of meaning: nature, structure and dynamics of semantic reality", M.: "Meaning", 1999, 487 p.

[7] M. Rokeach, "The Nature of Human Values", N.Y, 1973.

[8] G. Caplan, "Emotional crisis", The encyclopedia of mentalhealth, N. Y., 1963, vol. 2, pp. 521-532.

[9] V. Frankl, "Man in search of meaning", M.: "Progress", 1990, 368 p.

[10] A. I. Ushatikov and I. S. Ganishina, «"Psychological typology and classification of convicts held in correctional institutions of the Russian 
Tuberculosis: Prospective Cohort Study", BMJ Open Respiratory Research, 2017, no. 4, e000247.

penitentiary system: history and current status", International Prison Magazine, 2015, no. 4 (4), pp. 76-81.

[11] V. G. Deev, "Socio-psychological characteristics of young prisoners and the peculiarities of their re-education in ITU", Ryazan, 1982, $96 \mathrm{p}$.

[12] D. V. Sochivko, "Color Psychodynamics", M.: Moscow Psychological and Social Institute, 2009, $432 \mathrm{p}$.

[13] A. V. Napris, "The current state of the problem of motivation of employees and convicts in the light of the development of the penal system", Applied Legal Psychology, 2011, no. 1, pp. 185-193.

[14] N. A. Polyanin and D. V. Pestrikov, "The humanistic orientation of the personality of youth prisoners", M.-Ryazan, Academy of the Federal Penitentiary Service of Russia, Higher School of Psychology, 2016, $140 \mathrm{p}$.

[15] C. Kluckhohn, "Values and Value Orientations in the Theory of Action", Toward a General of Theory of Action, Cambridge, 1951.

[16] P. G. Zimbardo, "A New Perspective on Psychological Time: Theory, Researchand Assessment of Individual Differences in Temporal Perspective", Psychology of Time, Part 2, Special Issues, Theory and Modeli, 1998, no. 3.

[17] E. Klinger, "The search for meaning in evolutionary perspective and its clinicalimplications", The Human quest formeaning, Mahwah, N. Y. :Eribaum, 1998, pp. 27-50.

[18] K. M. Prenda, "Planning for the future: a life management strategy for increasingcontrol and life satisfaction in adulthood", Psychology and aging, 2001, vol. 16, pp. 206-216.

[19] I. Ganishina, G. Aksenova, and P. Aksenova, "Personal features of convicts with addictive behavior", Society, Integration, Education. Proceedings of the International Scientific Conference, 25-26 May, 2018, Higher Education, Rezekne, Rezekne Academy of Technologies, 2018, vol. VII, 320 p., pp. 34-47.

[20] R. Marcoa, A. I. Ribeiro, I. Zao, and R. Duarte, "Tuberculosis and Gender-Factors Influencing the Risk of Tuberculosis among Men and Women by Age Group", "Pulmonology", 2018, pp. 199-202.

[21] A. Z. Soh, C. B. E. Chee, Y. T. Wang, J. M. Yuan, and W. P. Koh, "Alcohol Drinking and Cigarette Smoking in Relation to Risk of Active
[22] R. T. Rohit, A. Niranjan, and P. A. Pawan, "Socio-Demographic Profile and Outcome of TB Patients Registered at DTC Rewa of Central India. Indian", Journal of Tuberculosis, 2018, no. 65, pp. 140-144.

[23] F. H. Gebreweld, M. M. Kifle, F. E. Gebremicheal, L. L. Simel, M. M. Gezae, and S. S. Ghebreyesus, "Factors Influencing Adherence to Tuberculosis Treatment in Asmara, Eritrea: A Qualitative Study", Journal of Health, Population, and Nutrition, 2018, no. 37, 1 p.

[24] F. B. Wurie, V. Cooper, R. Horne, and A. C. Hayward, "Determinants of Non-Adherence to Treatment for Tuberculosis in High-Income and Middle-Income Settings: A Systematic Review Protocol", BMJ Open, 2018, no. 8, e019287.

[25] E. A. Kendall, M. O. Fofana, and D. W. Dowdy, "Burden of Transmitted Multidrug Resistance in Epidemics of Tuberculosis: A Transmission Modelling Analysis", The Lancet Respiratory Medicine, 2015, no. 3, pp. 963-972.

[26] D. Heiden, P. Saranchuk, J. D. Keenan, N. Ford, A. Lowinger, and M. Yen, "An Examination for Early Diagnosis of Disseminated Tuberculosis in Patients with AIDS", The Lancet Infectious Diseases, 2016, no. 16, pp. 493-499.

[27] S. Ghatage, S. Aithal, and N. Angadi, "A Study on Reasons for Nonadherence to 99DOTS among HIV-Tuberculosis Coinfected Patients in Davanagere District, Karnataka", International Journal of Medical Science and Public Health, 2018, no. 7, pp. 805-808.

[28] V. N. Mashkov, "The practice of psychological support for leadership, management, management", SPb.: Speech, 2005, pp. 224-229.

[29] J. C. Crumbaugh, "The PIL Test: Administation, Interpretion, Uses Throry and Critique", International Forum for Logotherapy, 1988, vol. 11 (2), pp. 76-88.

[30] D. A. Leontiev, M. O. Kalashnikov, and O. E. Kalashnikova, "Factor structure of the test of life orientation", Psychological Journal, 1993, T. 14, no. 1, pp. 150-155.

[31] L. N. Sobchik, "The method of color choices - a modification of the eight-color Lusher test. Practical Guide", SPb.: Rech, 2007, 128 p. 